Logos Universality Mentality Education Novelty, Section: Philosophy and Humanistic Sciences

ISSN: 2284-5976 (print), ISSN: 2284-5976 (electronic)

Covered in: CEEOL, Index Copernicus, Ideas RePEc, EconPapers, Socionet

\title{
ONTOLOGICAL AND SEMIOTIC FOUNDATION OF VIRTUAL ECOLOGY. AN OVERVIEW
}

\section{Yury SHAEV}

Logos Universality Mentality Education Novelty, Section:

Philosophy and Humanistic Sciences, III (1), 15-29

The online version of this article can be found at:

http://lumenjournals.com/philosophy-and-humanisticsciences/

Published by:

Lumen Publishing House

On behalf of:

Lumen Research Center in Social and Humanistic Sciences 


\title{
Ontological and Semiotic Foundation of Virtual Ecology. An Overview
}

\author{
Yury SHAEV
}

\begin{abstract}
Virtual reality is now becoming a reality in which spends most of its time modern man. Virtual reality is an ontological and semiotic phenomenon. The ontology of virtual reality includes levels and topos deployment of virtual and defines the basic perceptual foundations of human interaction with it. Semiotic nature of virtual reality is that it is replete with various characters. Virtual Reality itself is a complex system of interrelated characters of different levels and types. Ontological and semiotic foundation of virtual reality allow us to formulate and retbink the basic contours of virtual ecology as a discipline of the harmonious interaction of man and his environment in a virtual-space information environment as circulation of signs and their impact on human rights. Modern ecological knowledge is closely linked to the question of philosophy and social theory can be drawn to the problems of virtual reality and the information space. Problems of the Internet of things could be considered in the approaches of the virtual environment.
\end{abstract}

\section{Keywords:}

information technologies, virtual reality, virtual world, ecology, virtual ecology.

1 Associate Professor, Pyatigorsk State Linguistic University, Russian Federation, existentia20065@yandex.ru.

Shaev, Y. (2015). Ontological and Semiotic Foundation of Virtual Ecology. An Overview. Logos Universality Mentality Education Novelty, Section: Philosophy and Humanistic Sciences, III (1), 15-29 


\section{Introduction}

Virtual reality is increasingly penetrates into everyday people's lives. Its various manifestations, ranging from communication by social networks and ending with virtual-interactive narrative, in which we can immerse, so it's become an integral part of everyone's life. These processes allow us to speak about virtual reality as of a certain ontological media phenomena (in the sense of how medial collateral ontological co-existence, which was described by Heidegger (2001) and Gadamer (2004).

It is worth to mention that now that modern man lives in a world where virtual reality is the most important part of the environment. In these circumstances, it is necessary to deeply understand the essence of the virtual space in the philosophical and ecological context and outline the basic principles of a virtual environment, which would be considered patterns of human interaction with the surrounding virtual environment. The virtual environment must take into account the special nature of the semiotic virtual reality, which cannot always be described by a mathematical model based on the information and structuralism semiotics.

\section{Main results}

We can mark multiple topos of ontological aspect of virtual reality. Firstly, it is the topos of communication and interaction by the language in the traditional sense. Currently, social networks, special programs allow us a comfortable communication, advertising and promotion of goods and services, conducting online business, the creation of information events for different events, the dissemination of news. In all these cases we can find a message as the most important syntagmatic element that makes possible the existence of the virtual space and media space as a phenomenon not only as ontological, but as semiotic. Needless to communicate via instant messaging (not always bidirectional) creates a field of ontological interaction between the actors and put them at the same space.

The theorists of hermeneutics, communicatively-oriented social theories gave great importance to the conversation as a topos of medial phenomenon and of exit point into being. Gadamer considered language in terms of communication and medial environment as a kind of ontological game that involves people and which takes place in them, as Mentality Education Novelty, Section: Philosophy and Humanistic Sciences, III (1), 15-29 
if they plays themselves. Gadamer singled medial-language component of the game and the game component of the language. Game is carried out in the language of its members, their addictive and involves the joint participation in orbit. Gadamer, as a theorist of the second half of the twentieth century, was thinking about the language and the game as a special phenomenon, which subsequently became closely associated with the virtual space. It is no accident, that video games and computer communications using multimedia technology has become almost the most iconic representations of virtual reality, though, of course, its scope is not limited.

Indeed, playing computer game, a person falls into a continuum of the game, something that makes him forget, even for a moment the reality. It is interesting to note that often the process of playing and socializing go hand in hand, for example, in the course of communication between participants of online games. In such situation, can be created a continuum of communication, interaction of a "common cause", which is involved in the topos of his being. On the one hand it can lead to positive results - communication and coexistence (though, of course, given the social atomicity of modern society, the desire for individualization of individuals, "the cult of himself", Gadamer's hermeneutics ideals of "authentic conversation”). On the other hand, escape from reality into the realm of "co-existence of the game" is not always achieves positive psychological and existential results. These phenomena have become quite common in the culture, not only among researchers of the virtual space, but also in literature and cinema. For example, the subject of care in the virtual world of computer games and virtual communication is devoted the film of Yana Comas Jan Komasa "Suicide Room" ("Sala samobójców”). The film's protagonist, is in a transitional age, have not received adequate attention and support of parents, and he tried to solve this problem into the virtual world, dealing with people, who also experience psychological problems. This film ends very tragically - the protagonist deprives himself of life.

There are topos of presence and immersion in virtual narrative, which are presented be media phenomenon such as computer video games and interactive cinema. In this case, the effect can be achieved with a more complete immersion in virtual narrative, and with the effect of the removal. With regard to the effect of immersion, there is, in 
addition to the aspects outlined above, a rather high level of development of virtual computer game narrative.

It should be noted that multimedia technologies that allow us to work with video and audio content represent the possibility to contact with the virtual world. The constitution of virtual reality in the human mind requires attention to the possibilities of the implementation of this contact. It is, above all, about the technical equipment and software tools that are focused on the production of "simulacra" virtual reality.

All of this is reflected in the virtual narrative, in particular in computer games, which, thanks to the involvement of many perceptual channels, appear immersive narrative, as a special stratum of reality. Virtual reality, in this respect acquires the features of reality, precisely because of the involvement of the perceptual apparatus. The same phenomenon occurs in an interactive movie in which by the choice of the viewer depends the development of the plot. It can be said that interactive cinema is ranging from humorous clips in which, for example, featured a young man, guard themselves from Lovelace and gets into various funny situations, if approved, the viewer / participant in his persistence in adventures to such serious computer game like Fahrenheit: The Indigo Prophecy, where in addition to non-linear storyline, excellent animation and music, creating a kind of depressive mood, we can highlight interesting effects narrative perception of reality, such as "circular" perception (player / viewer looks at the game world spinning around its axis, and the picture on monitor absorbed by the subconscious. A few comments should be made. The perception and its role in the narrative structure is regarding a heightened attention that there are currently various components of the human perceptual experience.

It should be noted the particular importance of visual perception. In order to ensure the reality of the different objects, phenomena, a man is important to see these objects, or imagine a situation of visual representation of certain things. Different ontological concept of European philosophers focused on the perception of being as a kind of spatial certainty, which can be seen. The same we could apply to the phenomenological research, from Husserl's phenomenology and ending social and phenomenological aesthetics. L. Wittgenstein compared visually iconic type of representation of certain facts with the 
device language, which also copies (or should replicate connections and relationships that exist in the real world).

Pearce drawn attention to principle of visual-iconic, and told that visual graphs that allow us to demonstrate the correlation of several variables as a visual representation of the best shows the device itself mark, as well as the presence in its indexical, iconic and conventional components (which, according to the concept of Pierce present in most of characters) (Shannon, Weaver, 1949). We must say that, historically, the traditional subject-predicate structure of the judgment requires, the fixation in the mind the subject and predicate of the predication as a certain definition, requires submission through visual images, not for nothing that the very act of symbolic substitution, which first made Aristotle. Visual-perceptual representation was important as well. Heidegger actively used such visual metaphors, such as "clearance being", "glimpse of life" (Eco, 1986).

Note also the fact that the fullness of immersion in a virtual narrative and other important components of sensory perception, such as auditory, sensory forms of perception. Now there are technologies that allow you to create these effects in the viewer / player, immersed in a virtual narrative (different simulators moving the body, the effect of vibration feedback, etc.). There may be a question - why is it important for the modern man to immerse into the narrative, which makes the modern reader / player / recipient has not satisfied the strength of his imagination, as it was with the world of literature? We believe that attention to the virtual narrative, and in general everything that is connected with the strengthening of the role of sensory components in cognition and daily life, are due to the feeling of being deep processes of modern man. It is possible that postmodern "tired" of culture, fixing various transcendental foundation of reality, all of these "beyond", "of", "in the ground", and seeps into everyday life. Despite the fact that the man in the street is often not a specialist in the field of philosophy or art history, general cultural and intellectual background makes itself felt. The same applies to the developers of computer games, virtual works of the very narrative in question.

Today, one or another computer game, doesn't have any significant philosophical connotations, does not have much chance of success (it certainly does not apply to genres, such as shooters, even though such games, containing a large quantity of pure "action" such as 
the Grand Theft Auto series is unthinkable today without the kind of philosophy). The same applies to interactive cinema, where the very linear plot indirectly suggests the possibility of certain mental and ideological perspectives. In addition, many, if not all, modern computer games are characterized by excellent graphics, sound, various special effects, that is, in the language of philosophy, semiotics and sign iconazation. All this is combined with a thoughtful, in most cases the plot. We believe that this situation demonstrates the desire of modern man to fill some fundamental lack of full contact with reality. And this contact must combine meditation and the search for deeper meaning and some natural spontaneity - the possibility of a full contact with the outside worlds in all its colours. About the longing for true existence, both in intellectual circles, and in the sphere of everyday life reflects one of the modern philosophers - Gumbreht. In his theory he proposes to distinguish between "the effects of values" and "effects of presence" of things of the real world.

According to Gumbreht, western metaphysical thought, tend to rely on the task of extracting the deep meanings of reality and are inherently hermeneutic, that is, to explain and interpret the world. These efforts have been accompanied by the search for disembodied sense of certain semantic and ontological foundations of reality. Now, it requires a new approach in the humanities, in the teaching of, and in the perspective of everyday life, which would have made it possible to develop an integrated system of non-hermeneutic categories that are not focused on search and meaning of certain phenomena. This representation by Gumbreht, fixed in a particular category of "presence". This perceptual experience, in its entirety allows things to "be", "to be present" in the actual present, and forgotten by the (mostly philosophy) side of knowledge and records the life and the ontological integrity of the subject. Historically it so happened that on the perceptual component of the "exit" to being, according Gumbreht forgotten Western philosophy, has experienced a decisive impact at the time of the Cartesian cogito (Gumbrecht, 2004).

This project attempts to do ontology as criticized study transcendental sense as the basis of different layers of being and attempt to revert to the effect of the presence, makes the possibility of the presence of things and their impact on us in particular with respect to the ontological sense netematizirovannyh givens. 
All this apply to the virtual narrative as a form of gaining the presence of the world. Playing a computer game, we are trying not only to update itself or another sense, but really "feel" themselves in space and time of this narrative.

Modern virtual narrative marks the philosophical problems of data, on the other hand, seeks to fill a fundamental lack of full human contact with reality in many dimensions. So, what we noticed it can be interpreted as a lack of physical existence and its peculiar attempt to compensate through immersion in virtual narrative.

In addition to the physical, in our view, modern man still feels the lack of historical and social existence. As to the first, then wrote about it many thinkers analyse the history, world history and attempts to recreate historical events in the form of the sense-event communications, fixed by a disciplinary historical research. Man is so constituted that the interest in the past it has manifested itself in many aspects of life and activity. However, we at all desire cannot have full historical existence, as man is a physically and historically limited. It is very well understood Heidegger, creating his project "Being and Time" and suggesting the abstract and philosophical way of compensation for the historical and cultural restrictions in acts Controller self-reflexive both "inside" and "outside" world historical and ontological space. It is clear that not all the townsfolk, and experts in the field of history available such abstract thinking operation. In addition, it is being withdrawn from the specific context of Heidegger, does little to solve the problem.

Virtual narrative partly solves this problem. It is important to note here is one thing, we do not absolutizing the value of the virtual narrative as the only way to remedy any deficiency in the historical existence of sensory-perceptual aspect. In addition to virtual narrative such a compensatory function is performed by a museum, preserving the material fragments of the past, and not just a museum. Past the era continue to "exist" in the present through the various material traces, such as architectural monuments, household items, cars and so on. We try to analyse what the modern computer games, which are an excellent example of a virtual narrative is so popular right now, not only among children and teenagers, but also among adults held people.

Computer game created on the basis of certain historical events, as well as a work of literature, such as the historical novel, the historical 
narrative in "pure" form a specific way relate fiction and historical reality. In a literary work the reader often played the role of passive recipient retrieves the text information regarding the meaning of certainevent communications, enjoying the "spirit of the age," created by the able pen of the author, the player in a sense, can become a "party" of historical events. The point here is not even the events themselves, because we are interested in the historical world, not only in terms of points of sign-events, as is often trying to make it a traditional historical narrative. For such a narrative events are some key moments from the associated thread of the narrative, that is, they are likely to perform a kind of functional role and give coherence to the narrative. It seems to us, the person plunges into a virtual narrative is not always chasing this connection, in fact so different historical inconsistencies, and sometimes ridiculous moments skipped player / recipient (which also happens to literature and cinema).

On the perceptual level, some recent games - are great samples of virtual narrative, in particular Assassin's Creed, recreate the medieval way of life, renaissance Italy, sometimes with great certainty (drawing on artefacts of the past, historical documents).

In the game Assassin's Creed the protagonist is a descendant of the famous assassins of past eras (plot is based on the confrontation of the two organizations - the Assassins and the Templars). Using a special computer that can read information from the DNA of his character gains the ability to restore the memories of their ancestors and like to live their lives over again in order to establish the whereabouts of a mysterious artefact - the Apple of Eden, giving control of the world.

In the first part of the game protagonist Desmond Miles simple American is going through the memories of his distant ancestor - Altair - Muslim fanatic of the sect of the Assassins, during the events of the Crusades.

In this game raises the problem of fragmentation of the human "I", which has become one of the commonplaces of modern philosophy. The human "I" in the modern world, if consciousness is the protagonist of the game is fragmented on the one hand, and on the other - trying to prevent fragmentation and "pull" into a single point all levels of meaning of their identity. The hero tries to cope with the disengagement, with the role of information relay to perform lofty goal. Lots integrity of the genetic code of a human being, saying the idea of 
seriality and mass production, repeatability of the phenotype in the links of the chain of generations (this is in tune with Baudrillard's arguments about the "serial" and "uniqueness" of works of art).

We also can mark the topos of presence and immersion in virtual narrative presented by such media phenomenon such as computer video games and interactive cinema. In this case, the effect can be achieved with a more complete immersion in virtual narrative, and the effect of the removal.

Last noticeable in cases when an individual tries to keep a distance between himself and the world of virtual narrative, to realize that all that happens to him in the virtual world - is an illusion. Often it can manifest itself in the reluctance to recognize their losses, such as the network computer games, which can be experienced psychologically negative, in an effort to avoid the dangers of the virtual world, its strong perceptual and psycho-emotional impact. Indirectly, such attempts to avoid discomfort and dangers of the virtual world are transferred to the reality and the individual tries to imagine the real world as an illusion and a computer simulation. Similar phenomena are quite common in recent years in situations of attempts of amateur to footage of various natural and man-made disasters, accidents, fights etc. and then distribute it in a variety of services: Instagram, You Tube and others.

In these cases, the individual use of the screen of the mobile gadget by the photos and videos means, but also as a kind of "shield", by which he is trying to dissociate itself from the reality of the events that happen to others, and to which it does not want to be involved. On the other hand, active use of photo and video tools for fixing the events that happen to a man speaks about the desire to convince ourselves and others (through placement of these materials, for example, in the social network) the reality of the events. In the world of the presence of virtual reality and its simulacrum, with the ability to create any image with the help of special computer programs it is important to raise the level of human reality in specific circumstances, in particular, ensure at the time of the events in the future that it really was. Sometimes you might get the feeling that this phenomenon is symptomatic - we miss the reality, so we want to get more and more evidence of its presence, co-presence. It's kind of the feeling of unreality of the world, which is manifested in such phenomena. The situation is somewhat reminiscent of the situation in the origin of the philosophy of early Greek philosophy, when the first 
Ionian philosophers first of all inquired: "What is it?". They seem to doubt the reality of the visible world, the illusory nature of feelings and looking for something that would think and say that being there. As you know, there originates the famous European tradition of being the search, his authentic presence even through reason (Descartes).

In modern philosophy, the question of being is one of the most contentious and controversial, in fact there is no single version of ontology, there are attempts to define and describe the various spheres of life. This inability of modern philosophy to develop a universal concept of being in common with the experience of comprehension of being in the world of everyday interaction with the outside world, including in terms of contact with virtual reality. Perhaps we feel the same lack of authenticity of life, wrote about the ancient Greeks, but it is now manifested in the new conditions. Virtual reality, doubling the world, spending very conditional boundary between the virtual and the real, creates a second level of illusory being, to put it in the spirit of the early Greek thinkers. The paradox of our situation is that we are trying to co-exist in both worlds - real and virtual, giving preference to one, then another.

You can fix the practical level of the presence of virtual reality and its image in the actual reality of human life. The presence of virtual reality in human life, or all kinds of reminders of her, and references to it are becoming more noticeable. It is worth recalling zones $\mathrm{Wi}-\mathrm{Fi}$ as an integral part of the urban space, nearly ubiquitous gadgets with Internet access, and other hardware and software of the presence of virtual reality in everyday life. Now it is impossible to imagine an individual who does not enjoy a variety of electronic devices. Most modern gadgets connected to the Internet. In recent years, actively discussed the issue of the Internet of Things as a special phenomenon in which devices can exchange information, process it and use it in a variety of automatic processes to address those or other problems (climate control, manage home appliances etc.) or unattended or with minimal. Thus these devices are the part of the environment that surrounds the human.

As you know, the environment in the traditional sense deals with the interaction between the organism (or organisms) and its environment in the broadest context. Especially now become more actually questions about the harmonious and balanced interaction between man, as well as with other beings and with each other or with 
the environment. As one of the key objectives of ecology is considered the environmental factors that can adversely affect the state of the organism or organisms. If as a starting point, we consider human individuals and virtual-information environment that surrounds it almost everywhere, the subject of a virtual ecology will be the harmonious interaction of man and society in general and virtual information environment. There are several registers or aspects of the virtual environment in their interactions with humans.

1. The level of physical interaction. These include all kinds of perceptual-physical interaction with the virtual space in a broader context. In this aspect, it is possible to analyse the possible forms of the negative impact of virtual information environment and information and computer technologies in general. Here we also can mark the negative impact on vision of a computer monitor, the electromagnetic radiation on the organism as a whole, the impact of awkward postures when sitting and working at the computer, about the dangers associated with the use of headphones on the roads and in the transport and other kinds of negative and potentially dangerous impact of information environment and information technologies. These include cases of disputed utility of modern high-tech devices. For example, "smart" watches, manufactured by Apple, according to experts may lead to the dispersal of attention and inability to concentrate on important matters. The man is constantly distracted by checking email, social networking and other functions. It is said that such defects affected and portable tablet computers, which in addition to the obvious benefits, can reduce the success of the training of pupils and students, they also can lose the ability to focus on long-term reading, for example, may deteriorate analytical skills etc.

2. The level of semiotic interactions. At this level occurs the circulation of signs within the virtual space, the creation and use of sign systems by persons, the circulation of what are called information. As examples of the negative impact of virtual space per person in the semiotic sense, we can give an example of semiotic noise as any irrelevant information that the user is forced to take. The noise in Shannon's model is something that prevents adequate perception of messages (Shannon, Weaver, 1949). As examples of semiotic noise we can cause the spam, intrusive advertising, requests to add as a "friend" of unknown people in social networks, irrelevant information, which 
may be issued as a result of a search query. Also, as the noise we can consider the news of various "public" in social networks, which are often advertising and have entertainment purposes, and in generally do not carry cognitive information, photos of episodes of personal life of people in a social network like Instagram. The need to communicate often with a considerable number of people within social networks can also be considered as a negative factor of the noise information. Apparently, due to this need, which can be regarded as a very tedious, receive great distribution various kinds of emoticons depicting not just emotion, but a whole range of situations, objects etc., which in fact turns them into a kind of icon with the possibility faster and more economical "package" of information. These phenomena can be regarded as examples of a kind of protective-adaptive mechanisms in the interaction with the virtual space, which can often act as a stressor that overloads the sensory-perceptual channels.

We must say that as a sign that we are considering quite different phenomena, relying more on the pragmatist conception of sign and interpretant as something that entails a certain reaction of the recipient (including physiological). Perhaps this is one of the main differences between the pragmatic version of semiotics, for example, structuralism. In structuralism semiotics referent of the sign - is an abstraction, it refers to what the sign in the semiotic "encyclopedia" (Eco, 1986). The physiological reaction to the sign remains "out of the equation." The pragmatic understanding of the mark takes into account the possible physiological and perceptual aspects related to the effects of the mark. In this sense, the information is not desired by carrier sense within structural semiotic logic, or is ignored or discarded. As part of the pragmatic concept even semiotic noise passes the process of semiotization, because it's may have as one of interpretant feeling of irritation, discomfort, fatigue etc.

\section{Conclusions}

It should be noted that often these two aspects of human interaction and virtual information space interpenetrate and interact in a dialectical unity, showing both the ontological and the semiotic nature of the virtual space.

We considered earlier virtual narrative uses the semiotic redundancy for the establishment of appropriate ontological effects. 
This applies to modern graphics, open world, which exists in many modern computer games and interactive cinema. Many games are attractive precisely due to this. Players have the opportunity, apart from the immediate storyline of the game, explore the surrounding game world, which advocates a kind of semiotic space and ontological redundancy, repetition - often a player nice feel in a familiar game space. In this sense, we can say that virtual-gaming narrative has non ecological effect of semiotic redundancy. Here it should be noted that this phenomenon is a dialectical. On the one hand, redundancy seems to be something that is unnecessary and superfluous, as is an increase in the amount of information. On the other hand the redundancy information is not always a negative factor. In this respect, the virtual environment should take into account the philosophical and ontological aspects of the modern world. It is necessary to bear in mind certain inertia and orientation of European thinking on the search for meaning and values, the presence of a culture of research content in the form of abstraction. The Aristotelian division between matter and form, and the subsequent increase in attention to the form (not excluding the various versions of idealism, where the transcendental form) in European culture and philosophy played a role and philosophy has largely become guided by the form / meaning / idea, everything else is secondary and subordinate counting. In modern philosophy and culture in the process of strengthening of attention to material factors and perceptual basis of experience. Talking about this subject, we should study the factors and examples of information redundancy, which can play a positive role in the knowledge of being a modern man. In this sense, the virtual environment must be in close contact with modern philosophy.

Virtual ecology, as the impact of the virtual space changes ontological existence of modern man and in many ways generates it. It becomes one of the layers being a modern individual, as his toposes life span, the main occupation, work, entertainment, and other aspects of life that can develop harmoniously, or may be in a situation of disharmony. That's why we should study the virtual environment in the ontological dimension. The semiotic aspect of the ecology of the virtual space is an expanded understanding of semiotics, which takes into account not only the reference in structuralist way, but the noise phenomena that lie in the plane of semiosis broader context of the sign nature of virtual space. 
The semiotic aspect of the ecology of the virtual space is an expanded understanding of semiotics, which takes into account not only the reference in structuralist way, but the noise factors as phenomena that lie in the plane of semiosis. This understanding of the semiotic phenomenon allows to identify the main factors of virtual environment and to build a paradigm that takes into account the ontological and semiotic base.

\section{Acknowledgement:}

A shorter version of this conference paper has been accepted to be published in proceedings volume of the $6^{\text {th }}$ LUMEN International Scientific Conference: LUMEN Rethinking Social Action Core Values, 16- 19 April 2015, Iasi, Romania, in publishing by Medimond Monduzzi International Proceedings, Italy - publishing partner of LUMEN Association.

The paper is published within the Grant of the President of Russian Federation "Ontology of virtual space". MK-1139.2014.6

\section{References}

Heidegger, M. (2001). Being and Time. Oxford: Blackwell, 589 p.

Gadamer, H.-G. (2004).Truth and Method. London, New York: Continuum, $601 \mathrm{p}$.

Shannon C., Weaver, W. (1949).The Mathematical Theory of Communication. Urbana: University of Illinois Press, p. 5.

Eco, U. (1986). Semiotics and Philosophy of Language. Bloomington: Indiana University press, pp. 46-84.

Gumbrecht H.U. Production of Presence. What Meaning cannot convey. - Stanford: Stanford university press, 2004 - p. 43-50.

\section{Biodata}

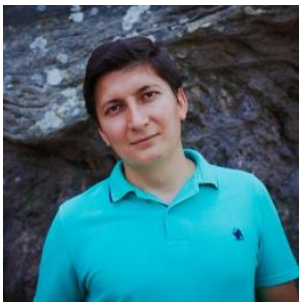

Yury Shaev is an associate professor (department of historical, social and philosophical disciplines, oriental studies and theology at Pyatigorsk State Linguistic University.

Shaev, Y. (2015). Ontological and Semiotic Foundation of Virtual Ecology. An Overview. Logos Universality Mentality Education Novelty, Section: Philosophy and Humanistic Sciences, III (1), 15-29 
Publications:

1. Shaev Y.Virtual reality: the effect and phenomenon of sign. Procedia social and behavioral sciences. - 2013.- pp.121-123. doi:10.1016/j.sbspro.2013.08.766

2. Shaev Y. Modern information technologies and identity. Medimond Monduzzi Editore International Proceedings division. 2013. - pp. 76-78.

3. Shaev Y. The multimedia technologies and the process of aesthetization of everyday life. - Proceedings of the International Congress on Interdisciplinary Behavior and Social Sciences - 2013. - pp. 535-537.

4. Samoylova E., Shaev Y. The semiotic of archetypes and images in the folklore of Ands region. -PROCEDIA: Social and behavioral sciences. - №92. -2013.- pp. 863-867. doi:10.1016/j.sbspro.2013.08.767

5. Samoylova E., Shaev Y. Europe in the virtual reality of computer games. - Medimond International Proceedings. Tradition and reform. Social reconstruction of Europe. 7-8- November 2013 Bucharest (Romania), pp. 331-335.

6. Shaev Y. Ontology of sense and new information technologies. - SGEM Conference on anthropology, archaeology, history and philosophy. DOI: 10.5593/sgemsocial2014B3 P. 753-758

7. Shaev Y. From the sociology of things to the "internet of things". - Procedia: Social and Behavioral Sciences, Volume 149, 5 September 2014, pp. 874-878. doi:10.1016/j.sbspro.2014.08.266

8. Shaev Y. Information technologies and layers of virtual identity. - Proceedings of SOCIOINT14- International Conference on Social Sciences and Humanities, pp. 291-294.

Shaev, Y. (2015). Ontological and Semiotic Foundation of Virtual Ecology. An Overview. Logos Universality Mentality Education Novelty, Section: Philosophy and Humanistic Sciences, III (1), 15-29 